\title{
EMPREENDEDORISMO PÚBLICO E ORIENTAÇÃO EMPREENDEDORA EM INSTITUIÇÕES FEDERAIS DE ENSINO
}

\section{Public Entrepreneurship and Entrepreneurial Orientation in Federal Education Institutions}

\author{
Simone Freitas Araújo Lima \\ Mestre em Administração. \\ Universidade Federal de Sergipe. Aracaju, SE. Brasil. \\ e-mail:sfreitasufs2013@gmail.com
}

\section{Rivanda Meira Teixeira}

Doutora em Administração. Professora do Programa de Pós Graduação em Administração (PROPADM). Universidade Federal de Sergipe. Aracaju, SE. Brasil. e-mail: rivandateixeira@gmail.com

\author{
Cristiane Feitoza Dantas \\ Mestre em Administração. \\ Universidade Federal de Sergipe. Aracaju, SE. Brasil. \\ e-mail:cristianefeitos@gmail.com
}

\section{Moisés Araújo Almeida}

Doutor em Administração. Professora do Programa de Pós Graduação em Administração (PROPADM). Universidade Federal de Sergipe. Aracaju, SE. Brasil. e-mail:moisesaraujoalmeida@gmail.com

\section{RESUMO}

Instituições acadêmicas públicas precisam ser orientadas à empreender e pesquisadores consideram de fundamental importância investigar a orientação empreendedora no interior dessas instituições. Esta pesquisa teve como objetivo analisar o nível de orientação empreendedora em duas instituições federais de ensino no Estado de Sergipe com base nas dimensões de Lumpkin e Dess (1996). Este estudo é quantitativo e o método de pesquisa adotado foi survey. Foi realizado mediante aplicação de questionário fechado com vinte e três assertivas, utilizando a escala Likert de 5 pontos. As unidades de análise foram duas instituições públicas no Estado de Sergipe: Universidade Federal de Sergipe (UFS) e Instituto Federal de Sergipe (IFS). Para análise dos dados utilizou-se análise fatorial das dimensões inovatividade, assunção de riscos, proatividade, agresssividade competitiva e autonomia. Os resultados evidenciaram a existência de orientação empreendedora, ainda que de forma incipiente, nas duas instituições do setor público, apontando a necessidade de reestruturação dessas instituições.

Palavras-chave: Empreendedorismo Público; Empreendedorismo Acadêmico; Orientação Empreendedora.

\section{ABSTRACT}

Public academic institutions need to be guided to entrepreneuship and therefore researchers consider crucial to investigate the entrepreneurial orientation within these institutions. This research aimed to analyze the level of entrepreneurial orientation in federal educational institutions in the State of Sergipe based on Lumpkin and Dess (1996) the dimensions. This study is quantitative and the research method used was survey. It was performed using a closed questionnaire with twenty-three assertions, using the Likert 5-point scale. The units of analysis were two public institutions in the State of Sergipe: Federal University of Sergipe (UFS) and Federal Institute of Sergipe (IFS). Data analysis used the factorial analysis of dimentions innovativeness, risk taking, proactiveness, competitive aggressiveness and autonomy. The results showed the existence of entrepreneurial orientation, although incipient, in both public sector institutions, pointing out the need for restructuring of these institutions.

Keywords: Public Entrepreneurship; Academic Entrepreneurship; Entrepreneurial Orientation. 


\section{INTRODUÇÃO}

As instituições do setor público que são, em regra, organizações sem fins lucrativos, buscam a satisfação do interesse público e demandam novas configurações de gestão. As transformações evidenciadas no setor público ao longo dos anos demonstram o aumento das expectativas de modernização e este processo tem sido relacionado às noções comportamentais e gerenciais, imbuídas de conceitos e práticas, que eram próprias e, até então, restritas à esfera das organizações empresariais (ZAMPETAKIS; MOUSTAKIS, 2010; FRANÇA; SARAIVA; HASHIMOTO, 2012).

Diante disso, o empreendedorismo público pode ser percebido como um processo que se desenvolve quando os indivíduos agem em busca de oportunidades para criação de valor (SHANE; VENKATARAMAN, 2000) e valor no setor público está ligado ao bem-estar do cidadão, reconhecendo-se que tal setor atua com obrigações, responsabilidades e objetivos distintos do setor privado (ZAMPETAKIS; MOUSTAKIS, 2010). No entanto, não se deve desprezar que essa atuação pode reunir a combinação de recursos públicos e privados para melhor exploração de oportunidades sociais (MORRIS; JONES, 1999).

Não obstante sua relevância, ainda são poucas as pesquisas sobre empreendedorismo no setor público. Além disso, os estudos existentes são fragmentados e trazem exemplos esporádicos sem qualquer desenvolvimento ou síntese de paradigmas de pesquisa disciplinar, traduzidos no comportamento empreendedor do setor público (SADLER, 2000).

Autores argumentam que houve crescimento na pesquisa sobre empreendedorismo público nos últimos anos, no entanto essa produção científica ainda é incipiente (SADLER, 2000; MORAIS et al., 2015). Ademais, reconhecem que ainda não se criou corpo teórico consolidado, visto que diversas expressões (polissemias) com vertentes diferentes foram encontradas para denominar o empreendedorismo público (MORAIS et al., 2015; ZAMPETAKIS; MOSTAKIS, 2010; MORRIS ; JONES, 1999).

As instituições acadêmicas, sejam estas públicas ou privadas, também são estruturas organicionais nas quais se evidencia o fenômeno do empreende- dorismo. O cenário econômico demanda uma readequação de seus atributos para assim potencializar o papel de verdadeiros agentes produtivos por meio da comercialização do conhecimento visando o desenvolvimento organizacional, econômico e social (ETZKOWITZ, 1983). Nas instituições privadas o foco empreendedor está nas parcerias estabelecidas com o setor produtivo tendo em vista o incentivo da comercialização da ciência. No caso das instituições públicas, observa-se seu modelo estrutural e administrativo podem representar um entrave para ações empreendedoras (FERRAS et al., 2014).

A orientação empreendedora (OE) surge como importante construto no âmbito do empreendedorismo, possibilitando por meio de processos, práticas e atividades o desenvolvimento organizacional baseado nas tomadas de decisões estratégicas e na implantação do comportamento empreendedor (LUMPKIN; DESS, 1996; COVIN; GREEN; SLEVIN, 2006). Nesse contexto, o empreendedorismo é visto como um meio de crescimento e renovação para organizações já existentes na forma do empreendedorismo corporativo, que se refere ao processo empreendedor no nível da organização e comportamento empreendedor no nível do indivíduo (STEVENSON; JARILLO, 1990; LUMPKIN; DESS, 1996; WIKLUND, 1999; FRANÇA; SARAIVA ; HASHIMOTO, 2012).

Não foram identificados estudos sobre OE voltados para setor público (SADLER, 2000; MORAIS et al., 2015). Carvalho et al. (2015) reforçam esse argumento e destacam que a $\mathrm{OE}$ é um construto que já foi utilizado no Brasil, no entanto, os estudos limitam-se as organizações orientadas para o mercado.

Esta pesquisa teve como objetivo analisar o nível de orientação empreendedora em instituições públicas com base nas dimensões de Lumpkin e Dess (1996). Particularmente, verificou-se como as dimensões inovatividade, assunção de riscos, proatividade, autonomia e agressividade competitiva influenciam no desempenho empreendedor das instituições de ensino públicas. Foram utilizadas neste estudo as assertivas adaptadas do estudo de Martens e Freitas (2013) sobre orientação empreendedora, as quais foram utilizadas no Brasil para mensurar o nível de OE em empresas privadas. 


\section{EMPREENDEDORISMO PÚBLICO}

Para Shane e Venkataraman (2000), empreendedorismo refere-se à descoberta e exploração de oportunidades lucrativas. Os autores consideram um problema a definição do empreendedor como uma pessoa que cria negócios, visto que isso desconsidera a variação da particularidade das oportunidades que diversas pessoas identificam, induzindo a negligência na medição de oportunidades pelos pesquisadores.

De acordo com Shane (2012), o empreendedorismo é a identificação, avaliação e exploração de uma oportunidade, mas destaca que a criação de um novo negócio pode existir dentro de uma organização, já que pode haver exploração de oportunidade dentro de uma organização já existente, como também a identificação de oportunidade em empregos anteriores pode levar a formação de um novo negócio.

O empreendedorismo tem sido definido como um processo controlável por dimensões implícitas de inovação, assunção de riscos e proatividade. Este processo aciona evento e agente empreendedores. A essência e elaboração de um novo conceito, ideias ou empreendimento dizem respeito ao evento, enquanto que o agente é o responsável por tornar o evento concretizável (MORRIS; JONES, 1999).

Segundo Morris e Jones (1999), as organizações não orientadas para o lucro, a exemplo das organizações públicas, buscam por meio da criação de valor as oportunidades necessárias para a eficiência na atuação empreendedora. No entanto, o setor público ainda enfrenta o desafio de importar do setor privado ideias, conceitos e modelos de gestão que direcionem as ações governamentais visando o mercado sem ameaçar o interesse público (BOX, 1999).

As organizações públicas são tidas como conservadoras e burocráticas e essas características peculiares podem dificultar o empreendedorismo. $\mathrm{O}$ empreendedorismo não é avesso a esfera pública e sim as suas estruturas tradicionais e burocráticas. Contudo, essas estruturas estão mudando em decorrência de recentes reformas na gestão pública, propiciando, no mínimo, o estímulo para práticas empresariais (SADLER, 2000).

Considera-se, muitas vezes, o empreendedorismo como a inovação, a criatividade, a criação de novas organizações ou de algum tipo de novidade.
Nesse sentido, a função de empreender pode ser realizada por diversos tipos de indivíduos nas mais variadas situações. Empreender pode ocorrer tanto no setor privado quanto no público, embora neste seja mais difícil de ocorrer, o que não significa dizer que não ocorre (KLEIN et al., 2010).

Para Bernier (2014), mesmo as recompensas sendo limitadas, as pessoas empreendem nas instituições públicas. Percebe-se que os governos agem sob pressões contraditórias, então é indispensável que os funcionários públicos inovem e modifiquem governos de forma que atinjam suas finalidades. Quando isso ocorre e os funcionários conseguem inovar são considerados empreendedores públicos.

Sadler (2000) avaliou vários fatores que facilitam o empreendedorismo corporativo no setor privado, dentre eles estão: tomada de decisão participativa ou descentralizada; não penalização de gestores por falhas em projetos arriscados; autonomia organizacional e ambiente hostil. Entretanto, esse autor evidenciou que o empreendedorismo corporativo na esfera pública é estimulado por fatores como: finalidades nitidamente compreendidas; equipe de trabalho unida; tomadas de decisão baseadas em poucos dispositivos integrados; estrutura de recompensa/ punição eficaz; pouca ou nenhuma intromissão política; autonomia organizacional e tomada de decisão participativa. $\mathrm{O}$ autor conclui que não é pertinente considerar o setor público como uma única estrutura operacional, pois há diferenças fundamentais entre governo local, empresas governamentais corporativas e as não-corporativas.

Para Currie et al. (2008), o empreendedor no setor público possui habilidades necessárias para coordenar iniciativas empresariais de forma favorável à governança do setor público e às necessidades dos stakeholders (partes interessadas), bem como reconhece oportunidades empresariais (extraindo vantagens delas) utilizando os recursos internos da organização e analisando seus indicadores políticos ou de mercado.

O empreendedorismo público é definido pela combinação de três propulsores distintos: os stakeholders, o empreendedor e o político. Neste sentido, muitos indivíduos podem possuir uma ou duas habilidades desses domínios, porém o que caracteriza o empreendedor no setor público é justamente 
a habilidade de incorporar e harmonizar esses três agentes (CURRIE et al., 2008).

Já Morris e Jones (1999) conceituam empreendedorismo público como o processo de criação de valor para os indivíduos, examinando possibilidades sociais e harmonizando recursos públicos e/ou privados. Dito isto, os autores ressaltam que algumas ferramentas do setor privado se aplicam ao setor público (como janela de oportunidade), algumas precisam ser adaptadas (como métodos de análise de oportunidade) e outras realmente não se aplicam (métodos de escolha de fontes de financiamento).

Diante disso, o empreendedorismo público não deve ser associado ao lucro econômico. As diversas facetas do empreendedorismo podem ser identificadas nas formas em que os indivíduos cooperam com seus colegas, nas formas em que organizam as tarefas diárias e nas formas em que respondem aos desafios da gestão (ZAMPETAKIS; MOSTAKIS, 2010).

\section{EMPREENDEDORISMO ACADÊMICO}

A multidimensionalidade atribuída ao empreendedorismo também permite analisá-lo a partir da perspectiva organizacional denominada University Entreperneurship ou Academic Entrepreneurship, destinada a estudar o empreendedorismo no interior das universidades, sejam estas públicas ou privadas (ROTHAERMEL; AGUNG; JIANG, 2007).

As instituições acadêmicas atualmente desempenham um novo papel no contexto social. Além da tradicional atuação no ensino e da função acadêmica da pesquisa científica, as universidades buscam na comercialização do conhecimento agregar o desenvolvimento econômico e social como parte de seus atributos (ETZKOWITZ, 1998). Assim, argumenta esse autor, as instituições acadêmicas empreendedoras são definidas como aquelas capazes de transformar o conhecimento produzido nas pesquisas em valor econômico e social para criar objetivos estratégicos definidos que guiem e expandam os horizontes das universidades.

As atividades empreendedoras nas instituições acadêmicas são consideradas fontes importantes para o desenvolvimento econômico, por exemplo, por meio da comercialização de patentes (SHANE, 2004); da privatização do ensino superior (BERNASCONI, 2005) e da transferência de tecnologia (YUSOF; SIDDIQ; NOR, 2012).

Desse modo, os conceitos "empreendedorismo universitário" e universidade empreendedora” atribuem às instituições acadêmicas a responbilidade na formação da expertise profissional, bem como a cooperação no sistema de inovações (parceria universidade-governo-empresa) para promover o avanço tecnológico, social e econômico global (IPIRANGA; FREITAS; PAIVA, 2010).

Quando tais instituições decidem transferir tecnologia e capitalizar o conhecimento atuando como verdadeiros agentes empreendedores, as chances de parcerias com empresas estabelecidas e a comercialização da ciência são maiores, possibilitando aos pesquisadores a liberdade para um profundo envolvimento com a pesquisa (DAMSGAARD; THURSBY, 2013).

Desse modo, o agente com perfil empreendedor, seja ele pesquisador, equipe ou gestor de pesquisa é apontado como peça fundamental para disseminar o empreendedorismo no interior das instituições acadêmicas. Esse agente tem atrelada à atividade empresarial as atividades de ensino e pesquisa bem como atividades internas (incentivos de apoio à pesquisa) e externas (formação de networking) que, quando bem articuladas, representam as bases para o empreendedorismo (LAMIDI, 2015).

As instituições acadêmicas públicas, em particular, se deparam com um duplo desafio. Além de enfrentar, como qualquer organização, as pressões de um ambiente competitivo e de se reinventar constantemente, necessitam implementar uma nova gestão que concilie a realização de atividades empreendedoras sem prejudicar a realização das atividades de políticas públicas (BOX, 1999).

Segundo Etzkowitz et al. (2000) o empreendedorismo nas instituições acadêmicas públicas tem um papel importante para o setor produtivo visto que a política entre governo e empresa, até então, limitava-se à relações estritamente comerciais. Assim, as esferas institucionais pública, privada e acadêmica que antes realizavam suas atividades de forma isolada, buscam nas ações conjuntas resultados que impactam decisivamente nos seus processos produtivos.

Apesar da atuação das instituições acadêmicas ser cada vez mais valorizada pelo poder público, as 
transformações nesse tipo de ambiente ainda se processam de maneira lenta (RASMUSSEN, 2008). Para obter melhor desempenho econômico e uma melhor relação com a indústria e a sociedade, Todorovic e Suntornpithug (2008) aduzem que as instituições acadêmicas públicas precisam ser orientadas à empreender e, por isso, consideram de fundamental importância investigar a orientação empreendedora e perceber como esta se processa no interior dessas instituições.

\section{ORIENTAÇÃO EMPREENDEDORA}

O empreendedorismo é um campo em plena expansão e permite ser estudado a partir de várias perspectivas. Uma dessas perspectivas é a orientação empreendedora $(\mathrm{OE})$, que tem despertado o interesse de estudiosos (MORRIS; KURATKO, 2002; CAMPOS; LA PARRA; PARELLADA, 2012). Compreender seu conceito e o quanto pode ser positiva para o desenvolvimento do ambiente organizacional podem determinar o sucesso de uma organização.

Mais voltada para o contexto privado, visando principalmente auxiliar as empresas na tomada de decisão e na obtenção de vantagem competitiva (COVIN; SLEVIN, 1991; LUMPKIN; DESS, 1996), a OE deve ser entendida a partir das estratégias adotadas por estas organizações (MILLER, 1983). Para este autor, pioneiro na criação deste construto, a performance de uma organização empreendedora está associada ao potencial de inovar em produtos e/ ou mercados e à capacidade de arriscar-se de forma proativa frente aos competidores. A partir de então, os elementos inovação, assunção de riscos e proatividade tornaram-se para muitos autores objetos de estudo e elementos definidores da orientação empreendedora assim chamados de dimensões (COVIN; SLEVIN, 1991; ZAHRA; COVIN, 1995; WIKLUND, 1999; COVIN; GREEN; SLEVIN, 2006).

Covin e Slevin (1991), por exemplo, propõem um modelo conceitual tendo as dimensões inovatividade, proatividade e assunção de riscos como parâmetros que moderam o comportamento organizacional e determinam a eficácia do processo empreendedor. Para os autores, a possibilidade de mensurar as dimensões ao nível da empresa permite a intervenção gerencial no comportamento organizacional, possibilitando direcionar o processo empreendedor para a obtenção de vantagem competitiva e para a melhoria do desempenho da organização.

A OE é, portanto, um componente estratégico cuja amplitude conceitual envolve resultados determinantes acerca da organização os quais delineiam os aspectos caracterizadores de sua gestão tais como preferências, crenças, valores e condutas pertinentes aos seus gestores e à organização como um todo (COVIN; GREEN; SLEVIN, 2006). Como resultante de seu caráter multidimensional, influencia no desempenho organizacional, podendo ser também influenciada pelo contexto ambiental cuja organização está inserida (LIZOTE et al., 2012); de modo que, quanto maior for a $\mathrm{OE}$, maior será a performance empresarial (FERNANDES; SANTOS, 2008).

O estudo da OE no campo do empreendedorismo privado tem sido utilizado, por exemplo, para avaliar o crescimento da taxa de vendas evidenciando que tomadas de decisões estratégicas autocráticas não comprometem a OE nas empresas (COVIN; GREEN; SLEVIN, 2006); explorar os efeitos da OE na gestão de topo de empresas familiares (SCIASCIA; MAZZOLA; CHIRICO, 2012); analisar as dimensões da OE e sua relação com o desempenho das empresas graduadas de incubadoras (LAZZAROTTI et al., 2015); analisar se os aspectos comportamentais do empreendedor líder de micro e pequenas empresas prestadoras de serviços favorecem a disseminação das dimensões da OE (BARRETO; NASSIF, 2014) e ainda para apontar os fatores que melhor explicam as dimensões da $\mathrm{OE}$ junto às empresas de software (MARTENS et al., 2013).

A orientação empreendedora torna-se, portanto, um construto de crucial importância para as organizações que desejam não só se destacar, mas, principalmente, que procura incorporar ações estratégicas empreendedoras buscando transformá-las em condutas e práticas organizacionais. Para Martens et al. (2013), esse construto possibilita o entendimento de que o empreendedorismo consiste não apenas em atividades operacionais, trata-se, portanto, de uma estratégia plena de desempenho organizacional.

Outros autores ampliaram o estudo da OE, a exemplo de Lumpkin e Dess (1996), que acrescenta- 
ram as dimensões autonomia e agressividade competitiva às já existentes, de modo que tais dimensões tanto podem ser analisadas conjuntamente quanto de forma independente (LUMPKIN; DESS, 1996; MARTENS; FREITAS, 2008). Lumpkin e Dess (1996) complementam que a eficácia da combinação das dimensões, as quais se resumem em inovatividade, proatividade, assunção de riscos, autonomia e agressividade competitiva possibilitam "novas entradas" para a organização, ou seja, ações que fomentam o comportamento empreendedor permitindo não só a criação de oportunidades como também a formação de boas práticas gerenciais que podem ser incorporadas à empresa. Considera-se, portanto, que estas dimensões configuram o construto da OE, o qual representa ações estratégicas resultantes de condutas, métodos e técnicas realizados pela organização durante a gestão de seus empreendimentos e nas tomadas de decisão.

A inovatividade representa a intenção da organização em propor, estimular e captar novas ideias, transformando-as em processos criativos que possam suceder em novos produtos, processos e/ou serviços. Para Miller (1983), a inovatividade é uma atividade complexa, mas que pode ser facilitada pelo empenho de tecnocratas e investimento em pesquisa e desenvolvimento (P\&D), assim como pela adequação da estrutura organizacional ao comportamento e processo criativos. Também se traduz em atingir as habilidades necessárias para a utilização das diversas tecnologias e métodos de produção que surgem e viabilizam o desenvolvimento de processos produtivos avançados (LUMPKIN; DESS, 1996).

A assunção de riscos aborda o potencial da organização em atuar de maneira ativa e ousada na perspectiva de novos empreendimentos (BARRETO; NASSIF, 2014). É também um atributo constantemente associado ao empreendedorismo e a depender do contexto em que estiver relacionado pode assumir diversos significados (LUMPKIN; DESS, 1996). Lumpkin e Dess (1996) destacam como riscos propensos a uma organização os associados ao negócio em si e que envolvem incertezas quanto ao sucesso quando não se pode prever o futuro; os atrelados aos investimentos, retornos financeiros e nuances do mercado e os riscos pessoais, aqueles que dizem respeitos aos gestores e suas tomadas de decisões.
A proatividade é considerada como essencial para a OE uma vez que sugere um panorama do futuro, consolidando-se em ações ou iniciativas que anteveem novas oportunidades de atuação em mercados emergentes ou para suprir necessidades a longo prazo (LUMPKIN; DESS, 1996). Consiste na habilidade organizacional de "antecipar as ações, enxergar a oportunidade ou procurar pela resolução de um problema iminente" (BARRETO, NASSIF, 2014 p. 184) de muito mais desenvolver a oportunidade e não somente de ir a sua busca no mercado (FERNANDES; SANTOS, 2008). Lumpkin e Dess (1996) acrescentam que ser proativo consiste em antecipar-se e agir visando demandas futuras de modo que a antecipação não representa necessariamente ser o precursor, ou seja, a ação proativa pode ocorrer em qualquer fase da atividade empresarial, seja na criação de algo novo ou mesmo influenciando tendências já existentes e em uso.

A autonomia consiste na ação independente de um indivíduo ou de uma equipe, a qual decorre da vontade auto-direcionada para a aquisição de oportunidades (LUMPKIN; DESS, 1996). Por meio de uma atitude autônoma, a organização evidencia a liberdade de atuação como um atributo inerente ao seu contexto organizacional (BARRETO; NASSIF, 2014), remetendo à independência nas ações, aspecto que para Martens e Freitas (2008) é de fundamental importância no processo empreendedor. Lumpkin e Dess (1996) complementam que o nível de autonomia exercido em uma organização pode variar de acordo com a centralização ou descentralização do poder e conforme o tamanho da estrutura organizacional, de modo que muitas empresas promovem a alteração de suas unidades operacionais visando o achatamento de hierarquias com o propósito de promover o processo de autonomia organizacional com um menor número de barreiras ou restrições.

A agressividade competitiva, por sua vez, representa o comportamento diretamente relacionado à disputa frente aos competidores por "posições e nichos de mercado" (LAZZAROTTI et al., 2015:679), ou seja, diz respeito aos meios necessários para o posicionamento da organização no mercado. Segundo Lumpkin e Dess (1996) assemelha-se à proatividade com a diferença que esta procura adaptar o ambiente buscando atender a uma demanda ou até mesmo 
criando uma nova, enquanto a agressividade competitiva diz respeito a como a organização reage à demanda já existente e à concorrência. Os autores ainda acrescentam que a agressividade competitiva pode implicar na utilização de métodos pouco tradicionais para responder as ações também acirradas da concorrência, visando obter um alto desempenho no mercado.

\section{METODOLOGIA}

Este estudo procura analisar o nível de orientação empreendedora em duas instituições de ensino públicas com base nas dimensões de Lumpkin e Dess (1996), conhecidas como: inovatividade, assunção de riscos, proatividade, autonomia e agressividade competitiva.

Esta pesquisa é quantitativa do tipo survey que é forma peculiar de pesquisa social empírica (BABBIE, 2001). Foi realizado mediante aplicação de questionário fechado com 23 assertivas, utilizando a escala Likert de 5 pontos.

O questionário é uma adaptação do instrumento elaborado por Martens et al. (2013) para analisar a OE em organizações privadas. Desse modo, a ferramenta de coleta desta pesquisa foi ajustada mediante a reestruturação de algumas assertivas de modo que a estrutura de análise ficasse claramente direcionada ao setor público. Desse modo, a pesquisa é em sua essência, o elo comum entre as organizações públicas e privadas. Para validação do estudo foi realizado um pré-teste objetivando verificar, entre outros aspectos, o entendimento do questionário bem como a especificação clara do foco de análise.

As unidades de análise foram duas instituições públicas no Estado de Sergipe: Universidade Federal de Sergipe (UFS) e Instituto Federal de Sergipe (IFS). A primeira é uma fundação pública, criada em 1968, com a missão de contribuir para o progresso da sociedade por meio da geração de conhecimento e da formação de cidadãos críticos, éticos e comprometidos com o desenvolvimento sustentável (UNIVERSIDA-
DE FEDERAL DE SERGIPE, 2010). A segunda é uma autarquia, criada em 2008, resultante da integração do Centro Federal de Educação Tecnológica de Sergipe e da Escola Agrotécnica Federal de São Cristóvão, e tem como missão oferecer educação profissional, científica e tecnologia de qualidade, em diferentes níveis e modalidades, para formação integral dos cidadãos capazes de estimular o desenvolvimento socioeconômico e cultural (INSTITUTO FEDERAL DE SERGIPE, 2016).

A escolha das duas instituições se deu por conveniência. Fizeram parte da pesquisa os servidores, docentes e técnicos administrativos ativos, de ambas as instituições. O horizonte temporal da pesquisa foi cross-sectional diante do escasso período de tempo para realização da pesquisa acadêmica (SAUNDERS; LEWIS; THORNILL, 2009). A survey foi realizada com o envio do questionário pelas instituições para todos os servidores mediante utilização da ferramenta Google Docs. O link foi enviado com as instruções para o preenchimento do questionário. A população da UFS foi de 2819 servidores e foram obtidas 119 respostas, equivalente a uma amostra de $4 \%$, enquanto a população do IFS foi de 1079 e foram recebidas 61 respostas, uma amostra de aproximadamente $6 \%$. A despeito de amostras maiores produzirem resultados substanciais, teve-se por objetivo obter uma amostra representativa de, no mínimo, 5 (cinco) vezes o número de assertivas do questionário, ou seja, 100 (cem) respondentes, a fim de atender os requisitos necessários para a utilização da técnica de análise fatorial (HAIR, et al 2009).

A pesquisa está segmentada em cinco grupos de assertivas: o primeiro grupo pretendeu verificar a influência da dimensão inovatividade mediante as assertivas de 1 a 6; o segundo grupo pretendeu verificar a influência da dimensão assunção de riscos mediante as assertivas de 7 a 10; o terceiro, a dimensão proatividade por meio as assertivas de 11 a 13; o quarto, a dimensão autonomia por meio das assertivas de 14 a 19 e por fim, a dimensão agressividade competitiva por intermédio das assertivas de 20 a 23 , conforme quadro a seguir: 
Quadro 1 Assertivas da OE em organizações públicas

Por favor, responda as questões de 1 a 23, correspondentes a Orientação Empreendedora em Organizações Públicas, utilizando a escala sendo 1 a sua total discordância e 5 a sua total concordância. Assinale com um $\boldsymbol{*}$ no item mais representativo da sua opinião

\section{Assertivas}

\begin{tabular}{|l|l|l|l|l|}
1 & 2 & 3 & 4 & 5
\end{tabular}

1. Os gestores incentivam a liderança competitiva e inovações, dedicando recursos materiais e financeiros para tal.

2. Os gestores incentivam atitudes originais e de experimentação para resolução de problemas.

3. A instituição inova em processos (administrativos, produção, mercado), dando preferência a projetar seus próprios processos e métodos de atuação.

4. A instituição utiliza fontes externas de recursos financeiros para inovação.

5. Os setores de coordenação dedicam-se à apreciação de atividades inovativas (próprias ou de terceiros).

6. O servidor consegue propor ideias novas em seu ambiente de trabalho.

7. Os gestores têm propensão a aprovar projetos mais arriscados (com foco em resultados).

8. Devido à natureza do ambiente, uma atitude ousada é necessária para alcançar os objetivos da organização.

9. A instituição tende a assumir riscos calculados; há preocupação com a mensuração dos riscos.

10. Diante de situações de tomada de decisão que envolve incerteza, a organização adota uma postura arrojada e agressiva com o objetivo de maximizar a probabilidade de explorar oportunidades em potencial.

11. Os gestores têm atitudes eficientes buscando melhorar a qualidade dos serviços prestados pela instituição.

12. O servidor não espera que te ordene o que fazer; está sempre atento às necessidades do seu ambiente de trabalho.

13. O servidor está sempre disposto a realizar seu trabalho da melhor maneira possível.

14. A instituição incentiva os servidores a trabalharem com liberdade para tomar decisão.

15. Os servidores desempenham um papel importante na identificação e seleção de oportunidades vantajosas para a instituição.

16. Existem práticas estabelecidas para o desenvolvimento do comportamento empreendedor na organização.

17. Os gestores são líderes autocráticos (autoritários).

18. Decisões importantes estão centralizadas na pessoa do chefe.

19. O servidor tem liberdade para tomar decisões que podem afetar seu ambiente de trabalho.

20. Os gestores consideram ações ativas em marketing importantes para a organização (imagem institucional, produtos e serviços, etc).

21. O servidor é estimulado a prestar seu serviço com a melhor qualidade possível.

22. As decisões institucionais são tomadas com foco no resultado.

23. As atividades institucionais são realizadas com orientação voltada para a satisfação do usuário (cliente).

Fonte Elaborado pelos autores, adaptado de Martens et al. (2013). 
Como já explicitado, o presente estudo buscou avaliar as dimensões da OE no ambiente público baseando-se no questionário adaptado do estudo realizado por Martens et al. (2013) que avaliou estas dimensões no ambiente privado. Para avaliação dos dados foi utilizada a análise fatorial, que é a técnica para identificar grupos ou agrupamento de variáveis (FIELD, 2009: 553), com auxílio do software SPSS (Statistical Package for Social Sciences) versão 20.

$\mathrm{Na}$ explicação das variâncias da amostra, a análise fatorial foi executada por meio do método de componentes principais, tendo como premissa básica que toda variância é comum. Este método identifica o grau de relevância dos fatores relacionados à explicação da variância total em ordem decrescente de percentual (o primeiro fator é o que possui o maior percentual de explicação e assim sucessivamente). Os fatores, também chamados variáveis latentes, resultam da presença de vários coeficientes de correlação significativos entre subconjuntos de variáveis e podem mensurar características de uma mesma dimensão. A análise fatorial consiste em reduzir para um número menor um conjunto de variáveis inter-relacionadas buscando retratar o nível máximo de variância comum (FIELD, 2009).

Para utilização da técnica de análise fatorial inicialmente foi necessário observar a existência de níveis de correlação satisfatórios entre as variáveis para êxito dos resultados da análise. Os testes de KMO (Kaiser-Meyer-Olkin) e esfericidade de Bartlett foram utilizados para confirmação da adequação da análise fatorial e correlação entre as variáveis (FIELD, 2009; Hair et al., 2009). Os testes de esfericidade de Bartlett apresentaram níveis de significância que induziram à rejeição de hipóteses nulas de que as matrizes de correlação sejam matrizes identidade em todas as dimensões analisadas. Os resultados dos testes de
KMO foram favoráveis à adequação das análises fatoriais de cada instituição.

\section{ANÁLISE E DISCUSSÃO DOS DADOS}

A análise fatorial, abordagem estatística que pode ser aplicada para compreender as inter-relações entre variáveis e delimitar as estruturas inerentes entre estas (HAIR et al., 2009), foi realizada observando o critério de comunalidade abaixo de $0,5 \mathrm{com}$ a finalidade de excluir aquelas variáveis que não se correlacionaram com o modelo, evidenciando assim as variáveis que mensuraram cada dimensão (REIS, 2001). Quanto maior o número de casos mais confiável é a análise fatorial e, considerando que a quantidade de respondentes da UFS foi maior que a do IFS, seus dados foram utilizados como parâmetro, eliminando as variáveis que obtiveram uma comunalidade abaixo deste critério.

Por meio da importância das comunalidades foram observados fatores que explicaram as variâncias de cada dimensão, identificando assim os fatores significativos, conforme tabelas por instituição (de 1 a 10) das dimensões $\mathrm{Na}$ dimensão inovatividade foram atribuídas seis assertivas que no questionário corresponde aos itens de 1 a 6 , conforme quadro 1 . Considerando o critério de comunalidade supramencionado, a variável que corresponde a assertiva 4 do questionário (A instituição utiliza fontes externas de recursos financeiros para inovação) foi eliminada, pois obteve valor de 0,242 e 0,310 para UFS e IFS respectivamente. Após a eliminação dessa assertiva em ambas as instituições, observou-se que as demais demonstraram coesão com esta dimensão. 
Tabela 1 Total da Variância Explicada da Inovatividade (UFS)

\begin{tabular}{c|c|c|c|c|c|c}
\hline \multirow{2}{*}{ Assertiva } & \multicolumn{5}{|c|}{ Autovalor Inicial } & \multicolumn{3}{c}{ Soma de extração das cargas ao quadrado } \\
\cline { 2 - 7 } & Total & \% de variância & \% Acumulado & Total & \% de variância & \% Acumulado \\
\hline 1 & 3,241 & 64,811 & 64,811 & 3,241 & 64,811 & 64,811 \\
\hline 2 & 0,726 & 14,517 & 79,328 & & & \\
\hline 3 & 0,445 & 8,9 & 88,228 & & & \\
\hline 5 & 0,333 & 6,652 & 94,88 & & & \\
\hline 6 & 0,256 & 5,12 & 100 & & & \\
\hline
\end{tabular}

Fonte: Elaborada pelos autores utilizando o software SPSS.

No caso do IFS a assertiva 1, que corresponde ao incentivo em P\&D (Pesquisa \& Desenvolvimento), liderança competitiva e inovações, representou $69,085 \%$ do total da variância explicada da inovatividade. Já na UFS esta assertiva foi de 64,811\%, evidenciando que esta instituição é menos criativa e com menor propensão em investimento em $P \& D$
(Miller, 1983), conforme tabelas 1 e 2. Esse autor também ressalta que essa dimensão é uma atividade complexa e que demanda adequação da estrutura organizacional, aspecto que pode justificar tais resultados se associarmos aos aspectos que caracterizam as instituições objetos deste estudo como sua razão de ser e tempo de existência.

Tabela 2 Total da Variância Explicada da Inovatividade (IFS)

\begin{tabular}{c|c|c|c|c|c|c}
\hline \multirow{2}{*}{ Assertiva } & \multicolumn{5}{|c|}{ Autovalor Inicial } & \multicolumn{3}{c}{ Soma de extração das cargas ao quadrado } \\
\cline { 2 - 7 } & Total & \% de variância & \% Acumulado & Total & \% de variância & \% Acumulado \\
\hline 1 & 3,454 & 69,085 & 69,085 & 3,454 & 69,085 & 69,085 \\
\hline 2 & 0,56 & 11,206 & 80,291 & & & \\
\hline 3 & 0,445 & 8,9 & 89,191 & & & \\
\hline 5 & 0,298 & 5,955 & 95,147 & & & \\
\hline 6 & 0,243 & 4,853 & 100 & & & \\
\hline
\end{tabular}

Fonte: Elaborada pelos autores utilizando o software SPSS.

Na dimensão assunção de riscos foram atribuídas quatro assertivas correspondentes aos itens de 7 a 10 do questionário. Foi eliminada a variável que corresponde a assertiva 8 , a qual devido à natureza do ambiente, uma atitude ousada é necessária para alcançar os objetivos da organização. Obteve-se valor de 0,140 para a UFS e 0,187 para o IFS e as demais demonstraram coesão. Estas observações estão representadas na tabelas 3 e 4 a seguir.

Tabela 3 Total da Variância Explicada da Assunção de Riscos (UFS)

\begin{tabular}{c|c|c|c|c|c|c}
\hline \multirow{2}{*}{ Assertiva } & \multicolumn{5}{|c|}{ Autovalor Inicial } & \multicolumn{3}{c}{ Soma de extração das cargas ao quadrado } \\
\cline { 2 - 7 } & Total & \% de variância & \% Acumulado & Total & \% de variância & \% Acumulado \\
\hline 7 & 1,966 & 65,549 & 65,549 & 1,966 & 65,549 & 65,549 \\
\hline 9 & 0,549 & 18,293 & 83,842 & & & \\
\hline 10 & 0,485 & 16,158 & 100 & & & \\
\hline
\end{tabular}

Fonte: Elaborada pelos autores utilizando o software SPSS. 
Na dimensão assunção de riscos o IFS também obteve maior percentual de variância $(72,625 \%)$ em relação à UFS $(65,549 \%)$ no que diz respeito à aprovação de projetos mais arriscados (assertiva 7 do questionário), evidenciando um potencial de atuação mais ativo e ousado ou que melhor reage frente às situações de incerteza.

Tabela 4 Total da Variância Explicada da Assunção de Riscos (IFS)

\begin{tabular}{c|c|c|c|c|c|c}
\hline \multirow{2}{*}{ Assertiva } & \multicolumn{5}{|c|}{ Autovalor Inicial } & \multicolumn{3}{c}{ Soma de extração das cargas ao quadrado } \\
\cline { 2 - 7 } & Total & \% de variância & \% Acumulado & Total & \% de variância & \% Acumulado \\
\hline 7 & 2,179 & 72,625 & 72,625 & 2,179 & 72,625 & 72,625 \\
\hline 9 & 0,467 & 15,563 & 88,188 & & & \\
\hline 10 & 0,354 & 11,812 & 100 & & & \\
\hline
\end{tabular}

Fonte: Elaborada pelos autores utilizando o software SPSS.

Para a dimensão proatividade foram atribuídas três assertivas correspondentes aos itens de 11 a 13 do questionário, sendo eliminada aquela correspondente à assertiva 11, já que os gestores têm atitudes eficientes buscando melhorar a qualidade dos serviços prestados pela instituição, com valores de 0,356 para a UFS e 0,554 para o IFS. Apesar da comunalidade do IFS ter valor superior a 0,5 esta assertiva foi eliminada devido à baixa comunalidade apresentada pela UFS, com o intuito de parametrizar a coesão das variáveis. Os resultados estão representados nas tabelas 5 e 6 seguintes.

Tabela 5 Total da Variância Explicada da Proatividade (UFS)

\begin{tabular}{c|c|c|c|c|c|c}
\hline \multirow{2}{*}{ Assertiva } & \multicolumn{3}{|c|}{ Autovalor Inicial } & \multicolumn{3}{c}{ Soma de extração das cargas ao quadrado } \\
\cline { 2 - 7 } & Total & \% de variância & \% Acumulado & Total & \% de variância & \% Acumulado \\
\hline 12 & 1,751 & 87,557 & 87,557 & 1,751 & 87,557 & 87,557 \\
\hline 13 & 0,249 & 12,443 & 100 & & & \\
\hline
\end{tabular}

Fonte: Elaborada pelos autores utilizando o software SPSS.

Nesta dimensão, a UFS e o IFS obtiveram respectivamente $87,557 \%$ e $88,240 \%$ de variância, referente ao servidor estar atento às necessidades do seu am- biente de trabalho, evidenciando discreta diferença entre estas instituições e podendo indicar a atuação de seus servidores visando demandas futuras.

Tabela 6 Total da Variância Explicada da Proatividade (IFS)

\begin{tabular}{c|c|c|c|c|c|c}
\hline \multirow{2}{*}{ Assertiva } & \multicolumn{5}{|c|}{ Autovalor Inicial } & \multicolumn{3}{c}{ Soma de extração das cargas ao quadrado } \\
\cline { 2 - 7 } & Total & \% de variância & \% Acumulado & Total & \% de variância & \% Acumulado \\
\hline 12 & 1,765 & 88,240 & 88,24 & 1,765 & 88,240 & 88,240 \\
\hline 13 & 0,235 & 11,760 & 100 & & & \\
\hline
\end{tabular}

Fonte: Elaborada pelos autores utilizando o software SPSS.

A dimensão Autonomia inicialmente não foi detectada na análise fatorial em virtude de não haver coesão entre as variáveis utilizadas para mensurar esta dimensão. Diferentemente das outras dimensões que apresentaram um único fator, demonstrando assim coesão entre as variáveis de cada dimensão, a auto- nomia apresentou dois fatores. Um fator relacionou as assertivas 14, 1516 e 19 do questionário e o outro fator, as assertivas 17 e 18, formando grupos de coesão distintos. Desse modo, realizou-se separadamente a analise desses dois fatores, evidenciando as assertivas 17 e 18 com maior coesão para esta dimensão. Res- 
salta-se que estas variáveis foram incluídas pelos autores deste estudo considerando o que Covin, Green e Slevin (2006) asseguraram em sua pesquisa que a OE teve um maior efeito sobre a taxa de crescimento de vendas em empresas cujas decisões operacionais e estratégicas foram deliberadas de maneira auto- crática. Além disso, tais assertivas foram escolhidas em virtude da natureza do setor público. O critério de cumunalidade para estas assertivas em ambas as instituições foi superior a 0,5 , obtendo valores de 0,657 e 0,811 para UFS e IFS respectivamente, conforme tabelas 7 e 8 .

Tabela 7 Total da Variância Explicada da Autonomia (UFS)

\begin{tabular}{c|c|c|c|c|c|c}
\hline \multirow{2}{*}{ Assertiva } & \multicolumn{5}{|c|}{ Autovalor Inicial } & \multicolumn{3}{c}{ Soma de extração das cargas ao quadrado } \\
\cline { 2 - 7 } & Total & \% de variância & \% Acumulado & Total & \% de variância & \% Acumulado \\
\hline 17 & 1,313 & 65,670 & 65,670 & 1,313 & 65,670 & 65,670 \\
\hline 18 & 0,687 & 34,330 & 100 & & & \\
\hline
\end{tabular}

Fonte: Elaborada pelos autores utilizando o software SPSS.

Nesta dimensão, o IFS apresentou um percentual de variância significativamente maior $(81,115 \%)$ do que a UFS $(65,670 \%)$ no que diz respeito à auto- cracia, evidenciando que aquela instituição tem maior liberdade de atuação em seu contexto organizacional.

Tabela 8 Total da Variância Explicada da Autonomia (IFS)

\begin{tabular}{c|c|c|c|c|c|c}
\hline \multirow{2}{*}{ Assertiva } & \multicolumn{4}{|c|}{ Autovalor Inicial } & \multicolumn{3}{c}{ Soma de extração das cargas ao quadrado } \\
\cline { 2 - 7 } & Total & \% de variância & \% Acumulado & Total & \% de variância & \% Acumulado \\
\hline 17 & 1,622 & 81,115 & 81,115 & 1,622 & 81,115 & 81,115 \\
\hline 18 & 0,378 & 18,885 & 100 & & & \\
\hline
\end{tabular}

Fonte: Elaborada pelos autores utilizando o software SPSS.

$\mathrm{Na}$ dimensão agressividade competitiva foram atribuídas quatro assertivas correspondentes aos itens de 20 a 23 do questionário, sendo eliminada aquela referente à assertiva 20 pois os gestores consideram ações ativas em marketing importantes para a orga- nização (imagem institucional, produtos e serviços, etc,) com valores de 0,348 e 0,570 para UFS e IFS respectivamente, conforme tabelas 9 e 10, devido aos mesmos motivos evidenciados na dimensão proatividade.

Tabela 9 Total da Variância Explicada da Agressividade Competitiva (UFS)

\begin{tabular}{c|c|c|c|c|c|c}
\hline \multirow{2}{*}{ Assertiva } & \multicolumn{5}{|c|}{ Autovalor Inicial } & \multicolumn{3}{c}{ Soma de extração das cargas ao quadrado } \\
\cline { 2 - 7 } & Total & \% de variância & \% Acumulado & Total & \% de variância & \% Acumulado \\
\hline 21 & 2,228 & 74,268 & 74,268 & 2,228 & 74,268 & 74,268 \\
\hline 22 & 0,457 & 15,22 & 89,488 & & & \\
\hline 23 & 0,315 & 10,512 & 100 & & & \\
\hline
\end{tabular}

Fonte: Elaborada pelos autores utilizando o software SPSS.

Nesta dimensão, o percentual de variância referente à prestação de serviço com maior qualidade foi de $78,166 \%$ para o IFS e $74,268 \%$ para a UFS, evidenciando que a primeira tem maior propensão a reagir diante de uma demanda já existente. 
Tabela 10 Total da Variância Explicada da Agressividade Competitiva (IFS)

\begin{tabular}{c|c|c|c|c|c|c}
\hline \multirow{2}{*}{ Assertiva } & \multicolumn{5}{|c|}{ Autovalor Inicial } & \multicolumn{3}{c}{ Soma de extração das cargas ao quadrado } \\
\cline { 2 - 7 } & Total & \% de variância & \% Acumulado & Total & \% de variância & \% Acumulado \\
\hline 21 & 2,345 & 78,166 & 78,166 & 2,345 & 78,166 & 78,166 \\
\hline 22 & 0,404 & 13,467 & 91,634 & & & \\
\hline 23 & 0,251 & 8,366 & 100 & & & \\
\hline
\end{tabular}

Fonte: Elaborada pelos autores utilizando o software SPSS.

Após verificação dos percentuais de variância comum explicados pelas variáveis, estruturou-se o quadro de dimensões que retrata a OE. Os valores dessas dimensões foram calculados pela média das médias de cada variável que compuseram as dimensões, depois de eliminadas aquelas que não estavam coesas, já que não explicavam minimamente a dimensão. A tabela 11 permite visualizar estes resultados.

Tabela 11 Média e Desvio-Padrão das Dimensões por Instituição

\begin{tabular}{l|l|c|c}
\hline \multirow{2}{*}{ Dimensão } & \multicolumn{2}{c}{ Instituição } \\
\cline { 2 - 4 } \multicolumn{2}{l|}{} & UFS & IFS \\
\hline \multirow{2}{*}{ No de Respondentes } & 119 & 61 \\
\hline \multirow{3}{*}{ Inovatividade } & Média & 2,3361 & 2,4721 \\
\cline { 2 - 4 } & Desvio-padrão & 0,9139 & 0,94941 \\
\hline \multirow{3}{*}{ Assumir Riscos } & Média & 2,1457 & 2,1639 \\
\cline { 2 - 4 } & Desvio-padrão & 0,91507 & 0,91616 \\
\hline \multirow{3}{*}{ Proatividade } & Média & 3,2563 & 2,7541 \\
\cline { 2 - 4 } & Desvio-padrão & 1,17687 & 1,08637 \\
\hline \multirow{3}{*}{ Autonomia } & Média & 3,4496 & 3,877 \\
\cline { 2 - 4 } & Desvio-padrão & 1,00717 & 1,07104 \\
\hline \multirow{2}{*}{$\begin{array}{l}\text { Agressividade } \\
\text { Competitiva }\end{array}$} & Média & 2,5098 & 2,6393 \\
\cline { 2 - 4 } & Desvio-padrão & 1,0977 & 1,09594 \\
\hline
\end{tabular}

Fonte: Elaborada pelos autores utilizando o software SPSS.

Embora tenha havido significativa diferença entre a quantidade de respondentes da UFS e do IFS, as médias e desvios-padrão das cinco dimensões analisadas apresentaram resultados semelhantes. Observou-se a presença de $\mathrm{OE}$ em ambas as instituições, apesar de modestos percentuais. Ressalta-se apenas uma pequena diferença nos percentuais referentes às dimensões proatividade e autonomia, indicando maior proatividade no ambiente da UFS, sugerindo uma maior propensão do servidor em desenvolver oportunidades, solucionando problemas iminentes. No que tange à autonomia, verificou-se maior relevância desta dimensão no ambiente do IFS, sugerindo maior liberdade de atuação do servidor.

Um ponto condizente com o estudo de Lumpkin e Dess (1996), diz respeito à ideia de independência entre as cinco dimensões de modo que estas podem ser percebidas de forma conjunta ou individualmente. Os autores também acrescentam que qualquer organização em que se observe efetivamente a presença de inovatividade, assunção de riscos, proatividade, autonomia e agressividade competitiva é empreendedora, aspecto que pode ser evidenciado, por exemplo, por meio dos processos e decisões organizacionais.

\section{CONCLUSÃO}

O presente trabalho teve como objetivo analisar o nível de orientação empreendedora em duas instituições de ensino do setor público com base nas dimensões de Lumpkin e Dess (1996). Para este fim, utilizou-se a análise fatorial demonstrando que as dimensões inovatividade, assunção de riscos, proatividade e agresssividade competitiva apresentaram um único fator, enquanto a dimensão autonomia apresentou dois fatores. Neste sentido, foram consideradas as assertivas que mais se correlacionaram com as dimensões analisadas.

Em relação à inovatividade, o destace foi para o incentivo em P\&D, inovações, liderança competitiva ou atitudes originais para resolução de problemas, apesar não ter sido evidenciado um alto percentual pra este fator em ambas as instituições. No entanto, 
notou-se que, na UFS, há possibilidade de os servidores sugerirem novas ideias no seu local de trabalho.

No que se refere à assunção de riscos, expressivo número de respondentes indicou que as instituições não aprovam projetos mais arriscados. Esse resultado é coerente com a literatura acerca da natureza do ambiente público, obediente à legislação sendo suas instituições ainda burocráticas e conservadoras, diferentes das empresas privadas que se arriscam mais por terem o lucro como objetivo (SADLER, 2000; ZAMPETAKIS; MOUSTAKIS, 2010).

A respeito da proatividade, foi identificada a disposição dos servidores em realizar suas atividades com qualidade e sem a necessidade de ordem imediata. A autonomia, por sua vez, evidenciou a gestão autocrática e a centralização administrativa. $\mathrm{Na}$ agressividade competitiva notou-se que, muito embora o servidor realize suas atividades da melhor forma possível, eles não são estimulados para isso.

Cabe ressaltar que apesar de o construto da orientação empreendedora ter sido estruturado tendo como perspectiva de análise as organizações privadas, pode-se inferir pelos resultados, ainda que de forma incipiente, a existência de orientação empreendedora no setor público, indicando a necessidade de reestruturação de seu arcabouço organizacional e adoção de práticas empreendedoras.

Mais relevante ainda é identificar nas instituições acadêmicas uma atuação organizacional empreendedora, denotando a necessidade de maior compreensão desta temática como forma de estimular o comportamento empreendedor dentro desse tipo de ambiente. A atuação empreendedora das instituições acadêmicas representa uma função importante para o setor produtivo não só por seu papel como fornecedor de capital humano, bem como de fonte para novas organizações (ETZKOWITZ et al., 2000).

Os aspectos limitantes deste estudo estão relacionados às questões de disponibilidade e interesse dos respondentes em participar da pesquisa. A participação de servidores técnicos pode ser considerada um viés para o estudo em decorrência de tais profissionais desempenharem, cotidianamente, atividades burocráticas. Cabe ressaltar que a inclusão desses profissionais foi deliberada, uma vez que buscou-se analisar a OE nas instituições escolhidas a partir de uma macro perspectiva, com foco nas organizaçãoes como um todo e não somente como produtoras de conhecimento. Nesse sentido, para estudos futuros sugere-se a ampliação da pesquisa com maior número de respostas em um número maior de instituições públicas, bem como a delimitação do estudo da $\mathrm{OE}$ nas universidades públicas a partir da perspectiva de produtoras e disseminadoras de conhecimento.

\section{REFERÊNCIAS}

BABBIE, Earl. Métodos de pesquisa de survey. Belo Horizonte: Editora da UFMG, 2001.

BARRETO, João C.; NASSIF, Vânia Maria. J. O empreendedor líder e a disseminação da orientação empreendedora. Revista Brasileira de Gestão de Negócios, v. 16, n. 51, p. 180-198, 2014.

BERNASCONI, Andrés. University entrepreneurship in a developing country: The case of the P. Universidad Católica de Chile, 1985-2000. Higher Education, v. 50, n. 2, p. 247-274, 2005.

BERNIER, Luc. Public enterprises as policy instruments: the importance of public entrepreneurship. Journal of Economic Policy Reform, v. 17, n. 3, p. 253-266, 2014.

BOX, Richard C. Running government like a business implications for public administration theory and practice. The American Review of Public Administration, v. 29, n. 1, p. 19-43, 1999.

CAMPOS, Héctor M.; LA PARRA, José P. N.; PARELLADA, Francesc S. The entrepreneurial orientation-dominant logic-performance relationship in new ventures: an exploratory quantitative study. $B A R$ - Brasilian Administration Review, v. 9, n. SPE, p. 60-77, 2012. 
CARVALHO, Eduardo G. C.; GANDIA, Rodrigo M.; FERREIRA, Cassiano A.; SUGANO, Joel Y. Entrepreneurial orientation in Brazil: a meta-analysis of quantitative studies. In: XXXIX ENCONTRO DA ASSOCIAÇÃO NACIONAL DOS PROGRAMAS DE PÓS-GRADUAÇÃO EM ADMINISTRAÇÃO, 2015, Belo Horizonte. Anais... Belo Horizonte: Anpad, 2015.

COVIN, Jeffrey G.; GREEN, Kimberly M.; SLEVIN, Dennis P. Strategic process effects on the entrepreneurial orientation-sales growth rate relationship. Entrepreneurship Theory and Practice, v. 30, n. 1, p. $57-81,2006$.

COVIN, Jeffrey G.; SLEVIN, Dennis P. A conceptual model of entrepreneurship as firm behavior. Entrepreneurship Theory and Practice, p. 7-25, 1991.

CURRIE, Graeme; HUMPHREYS, Mike; UCBASARAN, Deniz; MCMANUS, Steve. Entrepreneurial leadership in the english public sector: paradox or possibility? Public Administration, v. 86, n. 4 , p. $987-1008,2008$.

DAMSGAARD, Erika F.; THURSBY, Marie C. University entrepreneurship and professor privilege. Industrial and Corporate Change, v. 22, n. 1, p. 183-218, 2013.

ETZKOWITZ, Henry. Entrepreneurial scientists and entrepreneurial universities in american academic science. Minerva, v. 21, n. 2, p. 198-233, 1983.

The norms of entrepreneurial science: cognitive effects of the new university-industry linkages. Research policy, v. 27, n. 8, p. 823-833, 1998.

Research groups as 'quasi-firms': the invention of the entrepreneurial university. Research policy, v. 32, n. 1, p. 109-121, 2003.
ETZKOWITZ, Henry; WEBSTER, Andrew; GEBHARDT, Christiane; TERRA, Branca R. C. The future of the university and the university of the future: evolution of ivory tower to entrepreneurial paradigm. Research policy, v. 29, n. 2, p. 313-330, 2000 .

FERNANDES, Daniel V. D. H; SANTOS, Cristiane P. Orientação empreendedora: um estudo sobre as consequências do empreendedorismo nas organizações. RAE-eletrônica, v. 7, n. 1, art. 6, 2008.

FERRAS, Robson P. R. et al. Empreendedorismo corporativo em organizações públicas: Um estudo em uma universidade pública. In: XXXVIII ENCONTRO DA ASSOCIAÇÃO NACIONAL DA ASSOCIAÇÃO NACIONAL DOS PROGRAMAS DE PÓS-GRADUAÇÃO EM ADMINISTRAÇÃO, 2014, Rio de Janeiro, Anais... Rio de Janeiro: Anpad, 2014.

FIELD, Andy. Descobrindo a estatística usando o SPSS. 2.ed., Porto Alegre: Artmed, 2009.

FRANÇA, Aurimar B.; SARAIVA, Jeferson; HASHIMOTO, Marcos. Orientação empreendedora como indicador do grau de empreendedorismo corporativo: fatores que caracterizam os intraempreendedores e influenciam sua percepção. REGEPE - Revista de Empreendedorismo e Gestão de Pequenas Empresas, v. 1, n. 3, 2012.

HAIR Joseph F.; ANDERSON, Rolph E.; TATHAM, Ronald L; BLACK, Willian C. Análise Multivariada de Dados. 6ed., Porto Alegre: Bookman, 2009.

INSTITUTO FEDERAL DE SERGIPE - IFS. Missão, visão e princípios norteadores. Disponível em: $<$ http://www.ifs.edu.br/a-instituicao/missao-visao-e-principios-norteadores $>$. Acesso em 16 jan. 2016.

IPIRANGA, A. S. R.; FREITAS, A. A. F.; PAIVA, T. A. O empreendedorismo acadêmico no contexto da interação universidade-empresa-governo. Cadernos EBAPE.BR, v. 8, n. 4, p. 676-693, 2010. 
KLEIN, Peter G.; MAHONEY, Joseph T.; MCGAHAN, Anita M.; PITELIS, Christos N. Toward a theory of public entrepreneurship. European Management Review, v. 7, n. 1, p. 1-15, 2010.

LAMIDI, Kafayat K. Empowering research entrepreneurial leadership for the development of entrepreneurial universities. Strategy, Marketing and Economics Department Business School, p. 1-8, 2015.

LAZZAROTTI, Fabio; SILVEIRA, Alissane L. T. da; CARVALHO, Carlos E.; ROSSETO, Carlos R.; SYCHOSKI, Jonatha C. Orientação empreendedora: um estudo das dimensões e sua relação com desempenho em empresas graduadas. Revista de Administração Contemporânea, Rio de Janeiro, v. 19, n. 6, art. 1, p. 673-695, 2015.

LIZOTE, Suzete A.; FARBER, Susana G.; VERDINELLI, Miguel D.; ROSSETO, Carlos R. Relação entre orientação empreendedora, desempenho e ambiente a partir da percepção dos gestores de cooperativas. In: ENCONTRO DA ASSOCIAÇÃO NACIONAL DA ASSOCIAÇÃO NACIONAL DOS PROGRAMAS DE PÓS-GRADUAÇÃO EM ADMINISTRAÇÃO, 27, 2010, Rio de Janeiro, Anais... Rio de Janeiro: Anpad, 2012.

LUMPKIN, G. T.; DESS, Gregory G. Clarifying the entrepreneurial orientation construct and linking it to performance. Academy of Management Review, v. 21, n. 1, p. 135-172, 1996.

MARTENS, Cristina D. P.; CARNEIRO, Karoline D. A.; BERGMANN, Daniel R.; FREITAS, Henrique M. R. Dimensões da Orientação Empreendedora em Empresas Brasileiras de Software. In: XXXVII ENCONTRO DA ASSOCIAÇÃO NACIONAL DA ASSOCIAÇÃO NACIONAL DOS PROGRAMAS DE PÓS-GRADUAÇÃO EM ADMINISTRAÇÃO, 2013, Rio de Janeiro. Anais... Rio de Janeiro: Anpad, 2013.
MARTENS, Cristina D. P.; FREITAS, Henrique M. R.. Orientação empreendedora nas organizações e a busca de sua facilitação. Revista Eletrônica de Gestão Organizacional, v. 6, n. 1, p. 90-108, 2008.

MILLER, Danny. The correlates of entrepreneurship in three types of firms. Management Science, v. 29, n. 7, p.770-791, 1983.

MORAIS, Mateus C. A.; VALADARES, Josiel L.; EMMENDOERFER, Magnus; TONELI, Dany. Polissemias do empreendedorismo no setor público. REGEPE - Revista de Empreendedorismo e Gestão de Pequenas Empresas, v. 4, n. 1, 2015.

MORRIS, Michael H.; JONES, Foard F. Entrepreneurship in established organizations: the case of the public sector. Entrepreneurship Theory and Practice, v. 24, n. 1, p. 71-71, 1999.

MORRIS, Michael H.; KURATKO, Donald F. Corporate entrepreneurship: entrepreneurial development within organizations. South-Western Pub, 2002.

RASMUSSEN, Einar. Government instruments to support the commercialization of university research: Lessons from Canada. Technovation, v. 28, n. 8, p. 506-517, 2008.

REIS, Elizabeth. Estatística multivariada aplicada. Lisboa: Edições Sílabo, 2001.

ROTHAERMEL, F. T.; AGUNG, S. D.; JIANG, L. University entrepreneurship: a taxonomy of the literature. Industrial and Corporate Change, v. 16, n. 4, p. 691-791, 2007.

SADLER, Robert J. Corporate entrepreneurship in the public sector: the dance of the chameleon. Australian Journal of Public Administration, v. 59, n. 2, p. 25-43, 2000.

SAUNDERS, Mark; LEWIS, Philip; THORNIL, Adrain. Research methods for business students. 5.ed. Harlow: Prentice Hall 2009. 
SCIASCIA, Salvatore; MAZZOLA, Pietro; CHIRICO, Francesco. Generational involvement in the top management team of family firms: exploring nonlinear effects on entrepreneurial orientation. Entrepreneurship Theory and Practice, 2013.

SELA, Vilma M.; SELA, Francis E. R.; FRANZINI, Daniela Q. Ensino do empreendedorismo na educação básica, voltado para o desenvolvimento econômico e social sustentável: um estudo sobre a metodologia" pedagogia empreendedora" de Fernando Dolabela. In: ENCONTRO DA ASSOCIAÇÃO NACIONAL DA ASSOCIAÇÃO NACIONAL DOS PROGRAMAS DE PÓS-GRADUAÇÃO EM ADMINISTRAÇÃO, 30, 2006, Salvador. Anais... Salvador: Anpad, 2006, v. 30, p. 1-12.

SHANE, Scott. Encouraging university entrepreneurship? The effect of the Bayh-Dole Act on university patenting in the United States. Journal of Business Venturing, v. 19, n. 1, p. 127-151, 2004.

Reflections on the 2010 AMR decade award: delivering on the promise of entrepreneurship as a field of research. Academy of Management Review, v. 37, n. 1, p. 10-20, 2012.

SHANE, Scott; VENKATARAMAN, Sankaran. The promise of entrepreneurship as a field of research. Academy of Management Review, v. 25, n. 1, p. 217-226, 2000.

STEVENSON, Howard H.; JARILLO, J. Carlos. A paradigm of entrepreneurship: entrepreneurial management. Strategic Management Journal, v. 11, n. 5, p. 17-27, 1990.
TODOROVIC, Zelimir W.; SUNTORNPITHUG, Nichaya. Multi-dimensional nature of university-based incubators-Towards an Enhanced Understanding. Journal of Enterprising Culture, v. 16, n. 4 , p. 385-410, 2008.

UNIVERSIDADE FEDERAL DE SERGIPE - UFS. Plano de desenvolvimento institucional 2010-2014. São Cristóvão/SE, 2010.

WIKLUND, Johan. The sustainability of the entrepreneural orientation-performance relationship. Entrepreneurship Theory and Practice, 1999.

YUSOF, Mohar; SIDDIQ, Mohammad S.; NOR, Leilanie M. Internal factors of academic entrepreneurship: The case of four Malaysian Public Research Universities. Journal of Entrepreneurship, Management and Innovation - JEMI, v. 8, n. 1, p. 84-115, 2012.

ZAHRA, Shaker A.; COVIN, Jeffrey G. Contextual influences on the corporate entrepreneurship-performance relationship: A Longitudinal Analysis. Journal of Business Venturing, v.10, p. 43-58, 1995.

ZAMPETAKIS, Leonidas A.; MOUSTAKIS, Vassilis. An exploratory research on the factors stimulating corporate entrepreneurship in the Greek public sector. International Journal of Manpower, v. 31, n. 8, p. 871-887, 2010. 